\title{
Advances in the diagnosis and management of diabetic distal symmetric polyneuropathy
}

Jacek Kasznicki

Department of Internal Medicine, Diabetology and Clinical Pharmacology, Medical University of Lodz, Poland

Submitted: 29 November 2012

Accepted: 14 April 2013

Arch Med Sci 2014; 10, 2: 345-354

DOI: 10.5114/aoms.2014.42588

Copyright $\odot 2014$ Termedia \& Banach

\section{Abstract}

Distal symmetric polyneuropathy (DSPN) is the most common chronic complication of diabetes mellitus. The pathogenesis of DSPN is not fully elucidated, but it is certainly multifactorial in nature and attributable to metabolic and microvessel disorders related to chronic hyperglycemia, diabetes duration, and several cardiovascular risk factors. Early diagnosis and appropriate management are extremely important, since up to $50 \%$ of DSPN cases may be asymptomatic, and patients are unaware of foot injury leading to foot ulcers and amputation. Simple, validated tests such as the Neuropathy Disability Score and/or Vibration Perception Threshold may be used to diagnose DSPN. Similarly, neurological dysfunction screening questionnaires should be used to assess the quality and severity of DSPN symptoms. Using both methods enables prediction of the prognosis of diabetic patients with DSPN. No causative treatment of DSPN is known, but the results of clinical trials indicate that several treatment options are highly effective in symptomatic treatment of painful DSPN. The appropriate treatment of DSPN may improve the outcome, preventing or delaying the development of numerous diabetic complications.

Key words: diabetes mellitus, distal symmetric polyneuropathy, pathogenesis, diagnosis, management.

\section{Introduction}

Diabetes is an important health problem for the aging population, since it affects at least $20 \%$ of patients over 65 years. Diabetic individuals have higher rates of premature death, functional disability, and coexisting illnesses compared to healthy subjects. Some of the most serious and deleterious complications of diabetes, e.g. foot ulcer, are associated with diabetic neuropathy. The diabetic neuropathies are heterogeneous, and differ in their symptoms, neurologic involvement, course, and risk covariates [1, 2].

Distal symmetric polyneuropathy (DSPN) is the most common, chronic complication of diabetes. Distal symmetric polyneuropathy predisposes patients to severe functional limitations including unremitting pain and unsteadiness. All patients with DSPN with or without foot deformities are at risk of serious neuropathic complications [3]. The end-stage complications of neuropathy such as foot ulceration and amputation are associated with a dramatic increase in health care costs and decrease in quality of life [3, 4].
Corresponding author: Jacek Kasznicki MD, PhD Department of Internal Medicine, Diabetology and Clinical Pharmacology Medical University of Lodz 35 Parzęczewska St 95-100 Zgierz, Poland Phone: +48 427144551 Fax: +48 427144551 E-mail: jacek.kasznicki@ umed.lodz.pl 
It is estimated that neuropathy may be present in up to $10 \%$ of patients with the diagnosis of type 2 diabetes mellitus (T2DM) and affects up to $50 \%$ of patients with long-term diabetes. However, there are no reliable data on the frequency of DSPN in different populations, which arises from the fact that there are no clear guidelines on its diagnosis. Additionally, the sensitivity and specificity of different methods of diagnosis of DSPN, as well as their threshold values, are still not uniformly determined. Methods regarded as gold standards in clinical trials are not useful in clinical settings, because they are time consuming and require special devices.

In this review we discuss pathogenesis, diagnosis and management of DSPN. We also emphasize the importance of assessing the signs and symptoms of DSPN in diabetic patients, since in this group of patients neurological examination is often omitted, unlike ophthalmological and nephrological assessment.

\section{Search strategy}

We searched using the electronic databases PubMed/Medline and Cochrane Central Register of Controlled Trials with the terms "diabetology", "diabetes mellitus", "neuropathy", "chronic sensorimotor", "distal symmetric polyneuropathy", "diabetes complication", "management of diabetic neuropathy", "epidemiological studies in diabetes" and "clinical trials in diabetes". Additionally, abstracts from national and international diabetological meetings were searched. Retrospective studies, and small studies with the number of patients below 100, as well as animal studies, were also included in this review.

\section{Distal symmetric polyneuropathy}

Distal symmetric polyneuropathy occurs both in T1DM and T2DM. Its onset is usually unnoticeable and many patients remain asymptomatic for a long period of time. Neurological deficits are often discovered by chance during routine neurological examination. On clinical examination, there is usually a symmetrical sensory loss in the feet, and sometimes also above the ankles and in the hands. The ankle and Achilles reflexes are usually reduced or absent. Motor weakness is not typical for DSPN. In case of pronounced, asymmetrical motor signs one should raise the suspicion of a nondiabetic etiology of the neuropathy [5]. Disturbed proprioception and abnormal muscle sensory function may lead to unsteadiness that is also recognized as a manifestation of DSPN [6]. Up to $50 \%$ of patients with DSPN may experience symptoms, most frequently pain. The symptoms are usually associated with the clinical signs of peripheral neuropathy, but may also occur in the absence of signs. There is no agreement on the frequency of the occurrence of painful neuropathy. The incidence of painful DSPN is estimated between 3\% and 25\%; however, painful neuropathy is often unreported and untreated [7-9]. Harris et al. observed painful symptoms in $27 \%$ of diabetic individuals [10]. In the same study $30 \%$ of T1DM patients and $36 \%$ of male and $40 \%$ of female T2DM patients experienced neuropathic symptoms. However, $10 \%$ of males and $12 \%$ of females in the nondiabetic population reported similar symptoms and the differences in prevalence rates of neuropathy in patients with and without diabetes decreased with age. The estimates of prevalence of painful neuropathy varied from 3\% to over $20 \%$ as assessed by other investigators [11]. It was also revealed that the presence of pain was associated only with severity of DSPN and neither demographic nor diabetes-related factors contributed to its occurrence [12]. The diagnosis of painful DSPN is a clinical one and depends on the subjective description of pain. In most cases symptoms are distal, symmetrical, and increase at night. Paresthesias and hyperesthesias are frequent. Patients often describe symptoms as prickling, deep aching, sharp, and burning [13].

Acute sensory neuropathy (ASN) is a variant of DSPN [13]. Many of the symptoms of ASN and DSPN are similar, but there are important differences in the onset, signs, and prognosis [14]. Severe pain, described as burning and deep aching, is the main symptom in all patients. Additionally, weight loss, depression, and erectile dysfunction in males are frequently reported. In most cases clinical examination reveals no pathology. Rarely allodynia and reduced ankle reflexes may be present. Acute sensory neuropathy is most often related to poor glycemic control and may follow an episode of ketoacidosis [15]. Achieving stable blood glucose control is crucial, as it enables resolution of symptoms within several months [15].

Chronic inflammatory demyelinating polyradiculoneuropathy (CIDP) is a severe and progressive form of polyneuropathy that develops in diabetic patients [16]. This condition, unlike DSPN, is treatable. A positive response to steroids, intravenous immunoglobulin, or chemotherapeutics further confirms the diagnosis of CIDP [17].

\section{Complications of distal symmetric polyneuropathy}

Diabetic foot ulcer is a common, severe complication of diabetes [3]. The prevalence of this complication in the diabetic population ranges from $2 \%$ to $10 \%$ [3]. It is estimated that $45 \%$ to $60 \%$ of all diabetic ulcerations are neuropathic, while up to $45 \%$ of cases are both neuropathic and isch- 
emic in nature [3]. The nature of diabetic foot ulceration is multifactorial, but unperceived trauma seems to be the leading cause [3]. Decreased pain sensation in the extremities results in increased risk of foot injury. The other risk factors are poor glucose control, duration of diabetes, as well as male gender, vascular disease, foot deformities, abnormal foot pressures, previous history of ulceration or amputation, and visual disturbances [3]. Diabetic foot ulcer is responsible not only for the decreased quality of life but also for the increaaed mortality of diabetic patients (Figure 1).

\section{Natural history and risk factors for the development of distal symmetric polyneuropathy}

Although DSPN is the most common complication of diabetes, there is limited information regarding its natural history. The results of epidemiological studies indicate that the duration and level of hyperglycemia are the most important factors in its development (Table I). In the first 5 years after diagnosis, in T1DM patients thermal thresholds increased more than vibration thresholds [18]. The increase in thermal thresholds was greatest in subjects with the highest glucose levels [18]. Nerve conduction was also affected in that interval. Small but statistically significant increases of vibration and thermal thresholds were found in patients with T2DM early in the course of disease [19].

The etiology of DSPN seems to be heterogeneous $[20,21]$. Distal symmetric polyneuropathy develops on a background of chronic hyperglycemia and total hyperglycemic exposure seems to be the most important factor [8]. Other potential

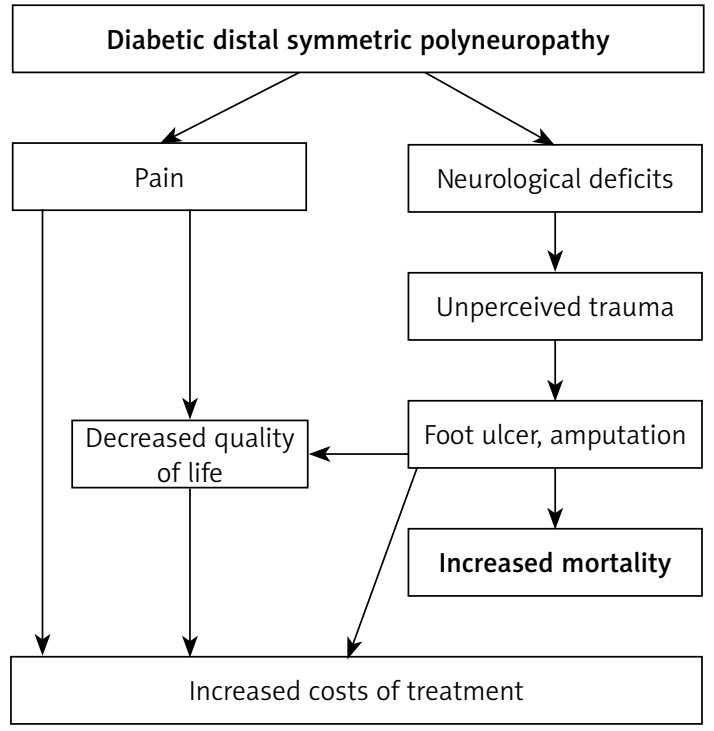

Figure 1. Burden of DSPN in diabetic patient

mechanisms contributing to the development of DSPN include oxidative injury, activation of the polyol pathway of glucose metabolism, deposition of advanced glycosylation end products within the nerves, and vascular insufficiency [8].

Young et al. revealed no differences in prevalence of DSPN by sex, but the prevalence of neuropathy in insulin-dependent patients was $12.9 \%$ and in non-insulin dependent patients 24.1\% [22]. Multiple logistic regression analysis found that age and duration of diabetes were both associated with DSPN in T2DM, whereas in T1DM the association was only seen for duration of diabetes. Overall, $20-40 \%$ of people with diabetes are estimated to have neuropathy (depending on how it is defined and measured) and about 5\% have a foot ulcer [22].

Table I. Risk factors for DSPN

\begin{tabular}{|c|c|c|}
\hline Study & Risk factors & Prevalence of DSPN \\
\hline Young et al. (1993) & $\begin{array}{c}\text { Age, duration of diabetes in T2DM, duration } \\
\text { of diabetes in T1DM }\end{array}$ & $20-40 \%$ \\
\hline Sorensen et al. (2002) & Duration of diabetes & \\
\hline Coppini et al. (2001) & Hyperglycemia, height & \\
\hline Harris et al. (1993) & $\begin{array}{c}\text { Duration of diabetes, degree of hyperglycemia, } \\
\text { glycosuria, hypertension }\end{array}$ & \\
\hline Pirart (1978) & Duration of diabetes, degree of hyperglycemia & $\begin{array}{l}>40 \%, 25 \text { years since } \\
\text { the diagnosis of } \mathrm{DM}\end{array}$ \\
\hline Eurodiab IDDM study (1996) & $\begin{array}{l}\text { Age, diabetes duration, } \mathrm{HbA}_{1 \text {, }} \text {, severe ketoacidosis, } \\
\text { weight, height, current cigarette smoking }\end{array}$ & $28 \%$ \\
\hline EDC Study (1989) & $\begin{array}{l}\text { Duration of diabetes, } \mathrm{HbA}_{1 \mathrm{c}}, \mathrm{HDL} \text { cholesterol, } \\
\text { hypertension, cigarette smoking }\end{array}$ & $37 \%$ \\
\hline Frankin et al. (1994) & Age, duration of diabetes, $\mathrm{HbA}_{1 c}$, insulin use & $28 \%$ in $\mathrm{T} 2 \mathrm{DM}$ \\
\hline Mitchell et al. (1990) & Lifetime cigarette smoking in T1DM & \\
\hline UKPDS (1998) & Increasing age and duration of diabetes & \\
\hline
\end{tabular}


In a number of studies DSPN was constantly related to diabetes duration [11], hyperglycemia [23] and height [23]. Harris et al. found that the combined sensory symptoms of DSPN were related to years since diagnosis, degree of hyperglycemia and glycosuria, and hypertension [10]. The Pirart study revealed strong associations of neuropathy with duration of diabetes and the degree of hyperglycemia [24]. After 25 years since the diagnosis of DM the prevalence of neuropathy was $>40 \%$. The EURODIAB IDDM study revealed that neuropathy was related to age, duration, haemoglobin glycosolated $\left(\mathrm{HbA}_{1 c}\right)$, and severe ketoacidosis, as well as weight, height, and current cigarette smoking [25]. In the EURODIAB IDDM Complications Study the overall prevalence of neuropathy was $28 \%$. In the Pittsburgh Epidemiology of Diabetes Complications Study (EDC) overall prevalence of DSPN was $37 \%$ at baseline, with substantial variation according to age [26]. In this study, DSPN was associated with diabetes duration, $\mathrm{HbA}_{11}, \mathrm{HDL}$ cholesterol, hypertension, and cigarette smoking. In the San Luis Valley Diabetes Study (SLVDS) the overall prevalence of DSPN was $28 \%$ in T2DM patients [27]. The SLVDS found that DSPN was related to age, diabetes duration, $\mathrm{HbA}_{1 \mathrm{c}}$, and insulin use. In a case-control study, DSPN was observed to be associated with lifetime cigarette smoking in individuals with T1DM, but not T2DM [28]. The results of the UKPDS study revealed that DSPN was more common with increasing age and duration of diabetes [29].

\section{Pathogenetic mechanism of distal symmetric polyneuropathy}

\section{Oxidative stress}

Although no mechanism is accepted as being the single cause of neuropathy, it is believed that reactive oxygen species (ROS) generated in vivo play an important role in nerve damage [18, 30]. In diabetic patients, poor glycemic control leads to chronic hyperglycemia. Oxidative stress may contribute to microvascular and neuronal deficits, as it is a direct result of hyperglycemia. The oxidation of elevated levels of glucose within the different cells including neurons stimulates production of ROS [30]. Increased generation of ROS such as superoxide, hydrogen peroxide and hydroxyl radical is the cause of oxidation and modification of the structure of cellular proteins, nucleic acids, and membrane lipids. Higher levels of peroxynitrate were found by Al-Nimer et al. [31] in biological fluids of T2DM patients compared to healthy subjects. The difference was highly significant for T2DM subjects with coexisting DSPN. Damage of the cellular structure and impairment of its function lead to cell necrosis and activation of genes involved in neuronal damage [32]. In diabetic patients increased oxidative stress may be associated not only with overproduction of reactive oxide species (ROS), but also with a significant decrease in the effectiveness of antioxidant defenses or both [33]. Insufficient anti-oxidative cellular mechanisms may also be involved in nerve damage. Single-nucleotide polymorphisms of the genes for mitochondrial (SOD2) and extracellular (SOD3) superoxide dismutases may confer an increased risk for the development of neuropathy [34]. The results of in vitro trials are partially confirmed by clinical trials with $\alpha$-lipoic acid (LA), a potent antioxidant. Diabetic patients randomly assigned to LA demonstrated an improvement in sural sensory nerve conduction velocity (NCV), sensory nerve action potential (SNAP), and tibial motor NCV. However, 2-year treatment with LA did not influence neuropathic disability score (NDS) [35]. Similar results were seen in another trial, in which diabetic patients were randomly assigned to intravenous LA for 3 weeks, followed by oral treatment. No change in the total symptom score was seen, but an improvement in the neuropathy impairment score after 3 weeks of intravenous therapy was maintained until the end of the study [36]. The SYDNEY study demonstrated a significant improvement in the neuropathy symptom score after treatment with racemic LA for 5 days/ week for 14 treatment cycles [37].

\section{Hyperglycemia and advanced glycation end products}

Chronic hyperglycemia results in the formation of advanced glycation end products (AGEs), which in turn through specific receptors (RAGEs) induce the production of cytokines and adhesion molecules [15]. It is suggested that AGEs may also participate in the development of DSPN. In the sural nerves obtained during leg amputations in diabetic and nondiabetic subjects, normal furosine, but significantly elevated pentosidine levels were found [38]. In patients with impaired glucose tolerance (IGT), the sural nerve amplitude does not differ significantly compared to those with normal glucose tolerance. The neuropathy associated with IGT is milder than the neuropathy associated with newly diagnosed DM, and it seems that small nerve fiber involvement may be the earliest detectable sign [15].

\section{Polyol pathway}

An association between increased flux through the polyol pathway and a reduction in NCV was observed in diabetic animals. Aldose reductase inhibitors (ARIs) tend to diminish these abnormalities [39]. A meta-analysis of randomized controlled 
trials of ARIs revealed significant improvement of median and peroneal motor NCV [15]. However, the drugs interfering with this pathway are mostly withdrawn due to serious side effects.

\section{Diagnosis}

The most simple definition of DSPN is "the presence of symptoms and/or signs of peripheral nerve dysfunction in people with diabetes after the exclusion of other causes" [40]. One should always remember that the diagnosis of DSPN is impossible without a clinical examination, since the absence of symptoms never indicates the $a b$ sence of signs. In patients with DSPN causes other than diabetes should always be excluded, such as neurotoxins and heavy metal poisoning, alcohol abuse, vitamin $B_{12}$ deficiency, renal disease, CIDP, inherited neuropathies, and vasculitis [41, 42]. The results of the Rochester Diabetic Neuropathy Study indicate that the etiology of up to $10 \%$ of cases of peripheral neuropathy in diabetic patients is nondiabetic [1]. It was observed that DSPN is associated with retinopathy and nephropathy and their occurrence increases the probability of diabetic etiology of polyneuropathy [8].

\section{Screening for distal symmetric polyneuropathy}

All patients should be screened for DSPN at diagnosis of T2DM and 5 years after the diagnosis of T1DM, and at least annually thereafter. The DSPN should be screened by examining pinprick, temperature, and vibration perception (using a $128-\mathrm{Hz}$ tuning fork), 10-g monofilament pressure sensation, and ankle and Achilles reflexes [40]. Combinations of more than one test have $>87 \%$ sensitivity in detecting DSPN. Abnormal results of nerve conduction tests, often subclinical, seem to be the first quantitative indication of DSPN. The feet should be examined and footwear inspected at each visit.

\section{Diagnosis of distal symmetric polyneuropathy}

Despite the lack of uniform guidelines on diagnosis and interpretation of results of neurologic examination, it is agreed that DSPN should not be diagnosed on the basis of one symptom, sign, or test alone. One should perform at least two tests (symptoms, signs, nerve conduction abnormalities, quantitative sensory tests) [40]. It is suggested that multiple site assessments have no advantage over single site testing [15]. For clinical trials or epidemiological studies, quantitative tests or electrophysiology should be performed. Tesfaye et al. proposed the classification of DSPN as possible, probable, confirmed, and subclinical based on the results of performed tests to detect symptoms and signs of neuropathy [8]. According to this classification, when nerve conduction (NC) values have not been assessed, diagnosis of DSPN cannot be confirmed, but only possible or probable.

\section{Quantitative sensory testing}

In diabetic patients the assessment of pressure sensation, vibration, thermal, and pain thresholds is used to diagnose subclinical neuropathy and progression of neuropathy, and screen for patients "at risk" for foot ulceration [43, 44]. These tests are often used as primary efficacy end points in clinical trials. One should always remember that quantitative sensory measurements are not fully objective. In an individual patient, the results strongly depend on the cooperation of the patient, as well as age, sex, body mass, and history of smoking and alcohol consumption [15].

\section{Devices for clinical screening}

Semmes-Weinstein monofilament exerting $10 \mathrm{~g}$ of pressure is the most widely used device for screening of diabetic neuropathy [7, 15]. A pressure sufficient to buckle the nylon filament should be applied to the device. There is however neither a consensus on how many sites should be tested, nor agreement on how many abnormal results at individual sites constitute an abnormal test result. It is usually recommended to screen at four sites per foot - the hallux and metatarsal heads 1,3 , and 5 [15]. Loss of 10-g monofilament perception and reduced vibration perception predicts foot ulcers with the sensitivity $>86 \%$ [45].

\section{Pinprick test}

Pinprick test is performed to assess the perception of pain. Most commonly perception of pain is assessed at each foot, namely at the hallux and metatarsal heads 1, 3, and 5. As with the previous test, there is no agreement on how many sites should be tested and how many abnormal results at individual sites constitute an abnormal test result.

\section{Vibration perception}

The graduated Rydel-Seiffer tuning fork $(128-\mathrm{Hz})$ is used to assess vibration perception [7]. The vibration thresholds are especially sensitive to detect mild or subclinical neuropathy and correlate well with other quantitative sensory testing (QST) measures $[15,46]$.

\section{Thermal thresholds}

Tip Therm enables assessment of the sensation of temperature. The loss of temperature sensation is associated with progression of neuropathy and foot ulceration $[47,48]$. Abnormal thermal thresh- 
olds are present in $75 \%$ of subjects with moderate-to-severe DSPN.

\section{Nerve conduction velocity}

The presence of NCV abnormalities reflects pathological changes in axons. It was observed that changes in NCV were not only related to glycemic control but also improve with effective therapy [7]. The NCV gradually diminishes in DSPN, with the average loss of $\sim 0.5 \mathrm{~m} / \mathrm{s} \times$ year. This test is useful in detecting subclinical cases of DSPN; however, NCV is rarely used in everyday clinical practice, except for atypical cases.

In accordance with international guidelines two clinical tests may be used to diagnose neurological deficits, namely the Neuropathy Disability Score (NDS) (Table II) or the Vibration Perception Threshold (VPT) [49]. Both these tests have been shown to predict outcomes, e.g., foot ulceration. Neuropathy should be diagnosed in subjects with an NDS score $\geq 3$ and/or a mean VPT of $\geq 25 \mathrm{~V}$. A modified Neuropathy Disability Score (NDS) has been used in several large studies and due to its simplicity can be used in everyday clinical practice.

Validated screening questionnaires, such as the brief Michigan Neuropathy Screening Instrument (MNSI), are helpful to record symptom quality and severity [50]. The severity of neuropathic pain and response to treatment of painful DSPN can be as sessed by the visual analog scale or the numerical rating scale [15]. A number of validated scales and questionnaires including the Neuropathic Pain Symptoms Inventory, Brief Pain Inventory, Neuropathic Pain Questionnaire, and McGill Pain Questionnaire may be used in clinical practice $[8,51]$.

\section{Other procedures}

The nerve biopsy, typically of the sural nerve, is rarely used in clinical practice, due to its inva- sive nature [8]. This technique allows detection of pathological changes in small nerve fibers. Nerve biopsy may detect unmyelinated fiber damage early in the course of DSPN, when myelinated nerve fiber morphology is still normal.

Skin biopsy is a minimally invasive procedure that enables morphometric quantification of intra-epidermal nerve fibers [52]. It was observed that the changes in intra-epidermal nerves correlate well with structural pathology in axons [8].

Corneal confocal microscopy is used to assess nerve structure [53]. This noninvasive technique enables the assessment of nerve structure in in vivo conditions. It was observed that the extent of corneal nerve damage and repair correlates with peripheral nerve function.

Recently several new tests and measurements were proposed in the diagnosis of DSPN. They assess both large-fiber function (tactile circumferential discriminator, steel ball-bearing, and automated nerve conduction) and small-fiber function (NeuroQuick and Neuropad). However, not all the tests are standardized, and their cost-effectiveness should be elucidated before they are used in everyday practice [54]. The usefulness of Neuropad, as a simple, non-invasive indicator of sudomotor dysfunction, was confirmed in clinical trials [55]. It was revealed that the results of Neuropad correlate well with NDS. It was suggested that determination of arginase activity in plasma in patients with DSPN may be useful in monitoring both its development and effects of therapy [56].

\section{Therapy}

\section{Prevention}

The first step in the treatment of any form of DSPN is intensive diabetes therapy aimed at near normoglycemia. It was confirmed that maintaining near-normal glycemia prevents the development

Table II. Modified Neuropathy Disability Score [56]

\begin{tabular}{|c|c|c|c|}
\hline \multicolumn{4}{|c|}{ Neuropathy Disability Score } \\
\hline & & Right & Left \\
\hline $\begin{array}{l}\text { Vibration perception threshold } \\
\text { 128-Hz tuning fork; apex of big toe; normal = can } \\
\text { distinguish vibrating/not vibrating }\end{array}$ & \multirow{3}{*}{$\begin{array}{c}\text { Normal }=0 \\
\text { Abnormal }=1\end{array}$} & & \\
\hline $\begin{array}{l}\text { Temperature perception on dorsum of the foot } \\
\text { Use tuning fork with beaker of ice/warm water }\end{array}$ & & & \\
\hline $\begin{array}{c}\text { Pin-prick } \\
\text { Apply pin proximal to big toe nail just enough to } \\
\text { deform the skin; } \\
\text { Trial pair = sharp, blunt } \\
\text { Normal = can distinguish sharp/not sharp }\end{array}$ & & & \\
\hline \multirow[t]{2}{*}{ Achilles reflex } & $\begin{array}{c}\text { Present }=0 \\
\text { Present } \text { with reinforcement }=1 \\
\text { Absent }=2\end{array}$ & & \\
\hline & NDS Total out o10 & & \\
\hline
\end{tabular}


and progression of DSPN [7]. The $\mathrm{HbA}_{1 \mathrm{c}}$ levels should be as close to normal values as possible before pharmacological treatment of DSPN is installed. Older adults with normal cognitive function should receive $\mathrm{HbA}_{1 \mathrm{c}}$ goals for younger adults.

The DCCT study demonstrated that reducing glucose levels in T1DM patients delayed or prevented the development of neuropathy as well as other microvascular complications such as retinopathy and nephropathy [57]. The results of the EDIC trial support this observation. The prevalence of neuropathy increased from $9 \%$ to $25 \%$ in former intensive and from $17 \%$ to $35 \%$ in former conventional treatment groups, 13-14 years after DCCT closeout. The observed difference was significant, and the incidence of neuropathy was significantly lower among former intensive compared to conventional treatment subjects [58].

The results of studies in patients with T2DM reveal that stable and optimal blood glucose control may prevent DSPN and autonomic neuropathy. However, not all studies support this observation. Data from the Rochester Diabetic Neuropathy Study indicate that the duration and severity of hyperglycemic exposure are associated only with the severity of neuropathy [59]. In the Veterans Affairs Cooperative Study on glycemic control and complications in type II diabetes (VACSDM), patients randomized to intensive versus convention- al therapy achieved a $2.07 \%$ difference in $\mathrm{HbA}_{1 \mathrm{c}}$, but they failed to demonstrate a significant difference in the progression of DSPN as well as autonomic neuropathy over 2 years [60]. Similarly, the Steno-2 Study failed to demonstrate an advantage of multifactorial intervention on measures of DSPN [61].

There are no conclusive data regarding modification of risk factor for DSPN other than hyperglycemia. However, as with other complications of diabetes, it seems sensible to control lipids and blood pressure, and avoid smoking and alcohol consumption.

\section{Pharmacological therapy of distal symmetric polyneuropathy}

The results of randomized clinical trials indicate that patients with painful DSPN may benefit from symptomatic pharmacological treatment (Table III) [7]. Level A evidence exists to support the use of tricyclic antidepressants, anticonvulsants, and serotonin and the norepinephrine reuptake inhibitor duloxetine [8]. There is also evidence from a randomized controlled trial supporting the use of opiates such as oxycodone and tramadol in painful DSPN [8].

Although effective treatment for DSPN is available, many agents have side effects that limit their

Table III. Pharmacological therapy of painful neuropathy (modified according to [38])

\begin{tabular}{|c|c|c|c|}
\hline Drug class & Drug & $\begin{array}{l}\text { Daily dose } \\
\text { [mg] }\end{array}$ & Side effects \\
\hline \multirow[t]{2}{*}{ Tricyclic } & Amitriptyline & $25-150$ & \multirow{2}{*}{$\begin{array}{c}\text { Dry mouth, urinary retention, fatigue } \\
\text { and drowsiness associated with anticholinergic } \\
\text { and central effects }\end{array}$} \\
\hline & Imipramine & $25-150$ & \\
\hline $\begin{array}{l}\text { Serotonin and } \\
\text { noradrenaline } \\
\text { reuptake inhibitor }\end{array}$ & Duloxetine & $60-120$ & $\begin{array}{l}\text { Drowsiness, nausea, loss of appetite, abdominal } \\
\text { pain, constipation, agitation, hallucinations, fever, } \\
\text { overactive reflexes, sweating, confusion, painful or } \\
\text { difficult urination, headache, severe skin reaction }\end{array}$ \\
\hline \multirow{2}{*}{$\begin{array}{l}\text { Selective serotonin } \\
\text { reuptake inhibitors }\end{array}$} & Paroxetine & 40 & \multirow{2}{*}{$\begin{array}{l}\text { Nanausea, dry mouth, headache, diarrhea, } \\
\text { nervousness, agitation or restlessness, reduced } \\
\text { sexual desire or difficulty reaching orgasm, erectile } \\
\text { dysfunction, rash, increased sweating, weight } \\
\text { gain, drowsiness, insomnia }\end{array}$} \\
\hline & Citalopram & 40 & \\
\hline \multirow[t]{4}{*}{ Anticonvulsants } & Pregabalin & $150-600$ & \multirow{4}{*}{$\begin{array}{l}\text { Dizziness, drowsiness, fatigue, nausea, tremor, } \\
\text { rash, weight gain }\end{array}$} \\
\hline & Gabapentin & $900-1,800$ & \\
\hline & Carbamazepine & $200-400$ & \\
\hline & Topiramate & Up to 400 & \\
\hline \multirow[t]{2}{*}{ Opioids } & Tramadol & $50-400$ & \multirow{2}{*}{$\begin{array}{c}\text { Dose-related respiratory depression, confusion, } \\
\text { hallucinations, delirium, urticaria, hypothermia, } \\
\text { bradycardia/tachycardia, orthostatic hypotension, } \\
\text { dizziness, headache, urinary retention, ureteric } \\
\text { or biliary spasm, muscle rigidity, myoclonus (with } \\
\text { high doses), flushing }\end{array}$} \\
\hline & Oxycodone CR & $10-60$ & \\
\hline Topical drugs & $\begin{array}{l}\text { Topical lidocaine in } \\
\text { the form of } 5 \% \text { patch }\end{array}$ & & $\begin{array}{l}\text { Local, at the site of administration - mild } \\
\text { irritation, redness, or swelling }\end{array}$ \\
\hline
\end{tabular}


use in clinical practice. Additionally, one should remember that no drug targeting a pathogenic mechanism is likely to be effective when the complication is well established.

\section{Tricyclic drugs}

The role of tricyclic drugs in the management of neuropathic pain was supported by the results of randomized clinical trials. The majority of data was gathered with amitriptyline, imipramine and desipramine. Amitriptyline, venlafaxine, and duloxetine seem to be equally effective [7]. These agents remain the first-line therapy for symptomatic DSPN. The use of tricyclic drugs is limited due to side effects. In the case of severe painful DSPN resistant to monotherapy with tricyclic drugs, these agents may be used in combination with other drugs such as anticonvulsants or nonpharmacological treatment. It was proved that venlafaxine is superior to placebo in relieving pain when added to gabapentin [7]. Titration of the dose of tricyclic drugs is advised to avoid side effects.

\section{Selective serotonin-reuptake inhibitors}

Results of clinical studies suggest that paroxetine, but not fluoxetine, is effective in relieving neuropathic pain [15]. Citalopram was also efficacious when given in the dose of $40 \mathrm{mg} /$ day, but was less effective than imipramine.

\section{Anticonvulsants}

Anticonvulsants have been used in the management of neuropathic pain for many years [7] Gabapentin, pregabalin and topiramate are proved effective. Pregabalin given twice daily may be used for relief of symptoms of DSPN [6]. Therapy with gabapentin in symptomatic DSPN resulted in significant pain relief together with reduced sleep disturbance when the drug was used in the dose of 900-3,600 mg daily [7]. Additionally, the side-effect profile also seems superior to that of the tricyclic drugs. Titration of the dose is advised to diminish the risk of side effects. Gabapentin is usually given in three daily doses, which may negatively influence compliance. In a randomized, placebo controlled study, Eisenberg et al. confirmed the efficacy of lamotrigine in neuropathic pain [62]. Limited evidence exists for the efficacy of phenytoin and carbamazepine in DSPN.

\section{Opioids}

Dextromethorphan, morphine sulfate, tramadol, and oxycodone may be used in the treatment of painful DSPN, and all drugs seem equally effective [7]. Dextromethorphan is probably effective in therapy of painful DSPN and improvement of quality of life [7]. The efficacy of tramadol in the management of patients with painful neuropathy was confirmed in a randomized controlled trial. Opioids such as oxycodone may be considered as add-on therapy in patients with severe painful neuropathy not responding to nonopioid medications. One should remember that these agents are associated with substantial side effects.

\section{Topical drugs}

Topical lidocaine in the form of a $5 \%$ patch is possibly effective in management of pain associated with DSPN [7].

\section{Antioxidant therapy}

$\alpha$-Lipoic acid (LA) is the most often used antioxidant; however, the results of numerous studies assessing its efficacy in the management of painful diabetic neuropathy give inconclusive results. Some studies demonstrate that supplementation with LA significantly improves antioxidant status even in patients with poor glycemic control. Large multicenter, randomized, double-blind placebo trials in Europe and North America demonstrated limited effects on neuropathic symptoms and results of electrophysiological testing $[34,63,64]$. However, the SYDNEY trial demonstrated that in travenous LA rapidly and significantly improves several neuropathic symptoms and nerve function in patients with DSPN [36].

\section{Other drugs}

The first clinical trials with aldose reductase inhibitors in DSPN took place 25 years ago, and currently only epalrestat is available, only in Japan. The data concerning its usefulness in DSPN are inconclusive [15]. Gamma-linolenic acid ( $\gamma$-LA, GLA) is a fatty acid found primarily in evening primrose oil. One year treatment with GLA resulted in improvement in electrophysiology and neurological deficits [15]. Treatment with ACE inhibitors was shown to improve electrophysiological measures of nerve function in mild neuropathy [15]. Isosorbide dinitrate was shown to improve painful symptoms, but its effect on deficits and electrophysiology are unknown. The results of a controlled study indicate that the topical application of isosorbide dinitrate spray to the feet was effective in relieving pain associated with DSPN [7]. A meta-analyses of studies with capsaicin, an alkaloid found in red pepper, revealed its efficacy in diabetic neuropathic pain. Capsaicin should not be used longer than 8 weeks, and this drug seems most useful in patients with localized symptoms [7] Nonpharmacological or physical therapies such as acupuncture and electrical stimulation may be 
useful as add-on therapy at any stage of diabetic neuropathy [7].

\section{Conclusions}

It seem necessary to actively screen for diabetic neuropathy, since up to $50 \%$ of DSPN cases may be asymptomatic. Validated screening questionnaires are helpful to record symptoms, and the Neuropathy Disability Score (NDS) and Vibration Perception Threshold should be used to diagnose neurological dysfunction. Both these tests have been shown to predict outcomes. In the diabetic patient one should always exclude other, treatable causes of neuropathies such as CIDP, vitamin $B_{12}$ deficiency, hypothyroidism, and uremia. Specific treatment of DSPN aimed at the underlying nerve damage is currently not available, but in the case of painful DSPN a number of effective symptomatic treatment options exist.

\section{Acknowledgments}

The work was supported by Polish Society of Metabolic Diseases.

\section{References}

1. Dyck PJ, Kratz KM, Karnes JL, et al The prevalence by staged severity of various types of diabetic neuropathy, retinopathy, and nephropathy in a population-based cohort: the Rochester Diabetic Neuropathy Study. Neurology 1993; 43: 817-24.

2. Bissinger A, Grycewicz T, Grabowicz W, Lubinski A. The effect of diabetic autonomic neuropathy on P-wave duration, dispersion and atrial fibrillation. Arch Med Sci 2011; 7: 806-12.

3. Frykberg RG, Zgonis T, Armstrong DG, et al. Diabetic foot disorders. A clinical practice guideline (2006 revision). J Foot Ankle Surg 2006; 45 (5 Suppl): S1-66.

4. Tonastiriotis C, Papanas N, Veletza S, Maltezos E. APOE gene polymorphisms and diabetic peripheral neuropathy. Arch Med Sci 2012; 8: 583-8.

5. Boulton AJM, Gries FA, Jervell JA. Guidelines for the diagnosis and outpatient management of diabetic peripheral neuropathy. Diabet Med 1998; 15: 508-14.

6. Van Deursen RW, Sanchez MM, Ulbrecht JS, Cavanagh PR. The role of muscle spindles in ankle movement perception in human subjects with diabetic neuropathy. Exp Brain Res 1998; 120: 1-8.

7. Bril V, England J, Franklin GM, et al. Evidence-based guideline: treatment of painful diabetic neuropathy. Report of the American Academy of Neurology, the American Association of Neuromuscular and Electrodiagnostic Medicine, and the American Academy of Physical Medicine and Rehabilitation. Neurology 2011; 76: 1758-65.

8. Tesfaye S, Boulton AJM, Dyck PJ, et al. Diabetic neuropathies: update on definitions, diagnostic criteria, estimation of severity, and treatments on behalf of the Toronto Diabetic Neuropathy Expert Group. Diabetes Care 2010; 33: 2285-93.

9. Dieleman JP, Kerklaan J, Huygen FJ, et al. Incidence rates and treatment of neuropathic pain conditions in the general population. Pain 2008; 137: 681-8.
10. Harris MI, Eastman R, Cowie C. Symptoms of sensory neuropathy in adults with NIDDM in the U.S. population. Diabetes Care 1993; 16: 1446-52.

11. Sorensen L, Molyneaux L, Yue DK. Insensate versus painful diabetic neuropathy: the effects of height, gender, ethnicity and glycaemic control. Diabetes Res Clin Pract 2002; 57: 45-51.

12. Mondelli M, Aretini A, Baldasseroni A. Distal symmetric polyneuropathy in diabetes. Differences between patients with a and without neuropathic pain. Exp Clin Endocrinol Diabetes 2012; 120: 45-50.

13. Apfel SC, Asbury AK, Bril V, et al. Ad Hoc Panel on Endpoints for Diabetic Neuropathy Trials. Positive neuropathic sensory symptoms as endpoints in diabetic neuropathy trials. J Neurol Sci 2001; 189: 3-5.

14. Thomas PK. Classification, differential diagnosis and staging of diabetic peripheral neuropathy. Diabetes 1997; 46 (Suppl. 2): S54-7.

15. Boulton AJM, Malik RA, Arezzo JC, Sosenko JM. Diabetic somatic neuropathies. Diabetes Care 2004; 27: 1458-86.

16. Stewart JD, McKelvey R, Durcan L, et al. Chronic inflammatory demyelinating polyneuropathy (CIDP) in diabetics. J Neurol Sci 1996; 142: 59-64.

17. Laughlin RS, Dyck PJ, Melton LJ, Leibson C, Ransom J, Dyck PJB. Incidence and prevalence of CIDP and the association of diabetes mellitus. Neurology 2009; 73 : 39-45.

18. Ziegler D, Mayer P, Mühlen H, Gries FA. The natural history of somatosensory and autonomic nerve dysfunction in relation to glycaemic control during the first 5 years after diagnosis of type 1 (insulin dependent) diabetes mellitus. Diabetologia 1991; 34: 822-82.

19. Sosenko JM, Kato M, Soto R, Goldberg RB. Sensory function at diagnosis and in early stages of NIDDM in patients detected through screening. Diabetes Care 1992; 15: 847-52.

20. Ceriello A. New insights on oxidative stress and diabetic complications may lead to "casual" antioxidant therapy. Diabetes Care 2003; 26: 1589-96.

21. Ulubay G, Ulasli SS, Bozbas SS, Ozdemirel T, Karatas M. Effects of peripheral neuropathy on exercise capacity and quality of life in patients with chronic obstructive pulmonary diseases. Arch Med Sci 2012; 8: 296-302.

22. Young MJ, Boulton AJM, MacLeod AF, et al. A multicenter study of the prevalence of diabetic peripheral neuropathy in the United Kingdom hospital clinic population. Diabetologia 1993; 36: 150-5.

23. Coppini DV, Wellmer A, Weng C, Young PJ, Anand P, Sonksen $\mathrm{PH}$. The natural history of diabetic peripheral neuropathy determined by a 12 year prospective study using vibration perception thresholds. J Clin Neurosci 2001; 8: 520-4

24. Pirart J. Diabetes mellitus and its degenerative complications: a prospective study of 4,400 patients observed between 1947 and 1973. Diabetes Care 1978; 1: 168-88.

25. Tesfaye S, Stevens LK, Stephenson JM; the Eurodiab IDDM study group. Prevalence of diabetic peripheral neuropathy and its relation to glycaemic control and potential risk factors: the Eurodiab IDDM complication study. Diabetologia 1996; 39: 1377-86.

26. Maser RE, Steenkiste AR, Dorman JS, et al. Epidemiological correlates of diabetic neuropathy: report from Pittsburgh Epidemiology of Diabetes Complications Study. Diabetes 1989; 38: 1456-61.

27. Franklin GM, Shetterly SM, Cohen JA, Baxter J, Hamman RF. Risk factors for distal symmetric neuropathy in NIDDM. Diabetes Care 1994; 17: 1172-7. 
28. Mitchell BD, Hawthorne VM, Vinik Al. Cigarette smoking and neuropathy in diabetic patients. Diabetes Care 1990; 13: 434-7.

29. UKPDS. Intensive blood glucose with sulphonylureas or insulin compared with conventional treatment and risk of complications in patients with type 2 diabetes. Lancet 1998; 352: 837-53.

30. Brownlee $M$. The pathobiology of diabetic complications a unifying mechanism. Diabetes 2005; 54: 1615-25.

31. Al-Nimer MS, Al-Ani FS, Ali FS. Role of nitrosative and oxidative stress in neuropathy in patients with type 2 diabetes mellitus. J Neurosci Rural Pract 2012; 3: 41-4.

32. Obrosova IG. How does glucose generate oxidative stress in peripheral nerve? Int Rev Neurobiol 2002; 50: 3-35.

33. Kasznicki J, Kosmalski M, Sliwinska A, et al. Evaluation of oxidative stress markers in pathogenesis of diabetic neuropaty. Mol Biol Rep 2012; 39: 8669-78.

34. Zotova EV, Chistiakov DA, Savost'ianov KV, et al. Association of the SOD2 Ala(-9)Val and SOD3 Arg213Gly polymorphisms with diabetic polyneuropathy in patients with diabetes mellitus type 1. Mol Biol (Mosk) 2003; 37: 404-8.

35. Reljanovic M, Reichel G, Rett K, et al Treatment of diabetic polyneuropathy with the antioxidant thioctic acid (alpha-lipoic acid): a two year multicentre randomized double-blind placebo-controlled trial (ALADIN II). Free Radic Res 1999; 1: 171-9.

36. Ziegler D, Hanefeld M, Ruhnau KJ, et al. Treatment of symptomatic diabetic polyneuropathy with the antioxidant alpha-lipoic acid: a 7-month multicentre randomized controlled trial (ALADIN III Study). ALADIN III Study Group. Diabetes Care 1999; 22: 1296-301.

37. Ametov AS, Barinov A, Dyck PJ, et al.; SYDNEY Trial Study Group. The sensory symptoms of diabetic polyneuropathy are improved with alpha-lipoic acid: the SYDNEY trial. Diabetes Care 2003; 26: 770-6

38. Ryle C, Donaghy M. Non-enzymatic glycation of peripheral nerve proteins in human diabetics. J Neurol Sci 1995; 129: 62-8.

39. Oates PJ. Polyol pathway and diabetic peripheral neuropathy. Int Rev Neurobiol 2002; 50: 325-92.

40. Boulton AJM, Vinik Al, Arezzo JC, Bril V, Feldman EL. Diabetic Neuropathies A statement by the American Diabetes Association. Diabetes Care 2005; 28: 956-62.

41. Wile DJ, Toth C. Association of metformin, elevated homocysteine, and methylmalonic acid levels and clinically worsened diabetic peripheral neuropathy. Diabetes Care 2010; 33: 156-61.

42. Freeman R. Not all neuropathy in diabetes is of diabetic etiology: differential diagnosis of diabetic neuropathy. Curr Diab Rep 2009; 9: 423-31.

43. Abad F, Diaz-Gomez NM, Rodriguez I, Perez R, Delgado JA Subclinical pain and thermal sensory dysfunction in children and adolescents with type 1 diabetes mellitus. Diabet Med 2002; 19: 827-31.

44. Kastenbauer T, Sauseng S, Sokol G, Auinger M, Irsigler K. A prospective study of predictors for foot ulceration in type 2 diabetes. J Am Podiatr Med Assoc 2001; 91: 343-50.

45. Miranda-Palma B, Basu S, Mizel MD, Sosenko JM, Boulton AJM. The monofilament as the gold standard for foot ulcer risk screening: a reappraisal (Abstract). Diabetes 2003; 52 (Suppl. 1): A63.

46. Hilz MJ, Axelrod FB, Hermann K, Haertl U, Duetsh M, Neundorfer B. Normative values of vibratory perception in 530 children, juveniles and adults aged 3-79 years. J Neurol Sci 1998; 159: 219-25.
47. Dyck PJ, Dyck PJB, Velosa JA, Larson TS, O’Brien PC; The Nerve Growth Factors Study Group. Patterns of quantitative sensation testing of hypoesthesia and hyperalgesia are predictive of diabetic polyneuropathy: a study of three cohorts. Diabetes Care 2000; 23: 510-7.

48. Shy ME, Frohman EM, So YT Arezzo JC, Cornblath DC, Giuliani MJ; Subcommittee of the American Academy of Neurology. Quantitative sensory testing. Neurology 2003; 602: 898-9.

49. Vileikyte L, Peyrot M, Bundy CE, et al. The development and validation of a neuropathic symptom and foot ulcer-specific quality of life instrument. Diabetes Care 2003; 26: 2549-55.

50. Feldman EL, Stevens MJ, Thomas PK, Brown MB, Canal N, Greene DA. A practical two-step quantitative clinical and electrophysiological assessment for the diagnosis and staging of diabetic neuropathy. Diabetes Care 1996; 17: $1281-9$.

51. Cruccu G, Anand P, Attal N, et al. EFNS guidelines on neuropathic pain assessment. Eur J Neurol 2004; 11: 153-62.

52. Lauria G, Merkies IS, Faber CG. Small fibre neuropathy. Curr Opin Neurol 2012; 25: 542-9.

53. Malik RA, Kallinikos P, Abbott CA, et al. Corneal confocal microscopy: a non-invasive surrogate of nerve fibre damage and repair in diabetic patients. Diabetologia 2003; 46: 683-8.

54. Papanas N, Ziegler D. New diagnostic tests for diabetic distal symmetric polyneuropathy. J Diabetes Complication 2011; 25: 44-51.

55. Papanas N, Paschos P, Papazoglu D, et al. Accuracy of the Neuropad test for diagnosis of distal symmetric polyneuropathy in type 2 diabetes. Diabetes Care 2011; 34: 1378-82.

56. Stojanovic I, Djordievic G, Pavlovic R, et al. The importance of L-arginine metabolism modulation in diabetic patients with distal symmetric polyneuropathy. J Neurol Sci 2013; 324: 40-4

57. The Diabetes Control and Complications Trial Research Group. The effect of intensive treatment of diabetes on the development and progression of long-term complications in insulin-dependent diabetes mellitus. N Engl J Med 1993; 329: 977-86.

58. Martin CL, Albers J, Herman WH, et al.; DCCT/EDIC Research Group. Neuropathy among the diabetes control and complications trial cohort 8 years after trial completion. Diabetes Care 2006; 29: 340-4.

59. Dyck PJ, Davies JL, Wilson DM, Service FJ, Melton LJ 3rd, O'Brien PC. Risk factors for severity of diabetic polyneuropathy: intensive longitudinal assessment of the Rochester Diabetic Neuropathy Study cohort. Diabetes Care 1999; 22: 1479-86.

60. Azad N, Emanuele NV, Abraira C, et al. The effects of intensive glycemic control on neuropathy in the VA Cooperative Study on Type II Diabetes Mellitus (VA CSDM). J Diabetes Compl 1999; 13: 307-13.

61. Gaede P, Vedel P, Larsen N, Jensen GV, Parving HH, Pedersen O. Multifactorial intervention and cardiovascular disease in patients with type 2 diabetes. $N$ Engl J Med 2003; 348: 383-93.

62. Eisenberg E, Luri Y, Braker C, Daoud D, Ishay A. Lamotrigine reduces painful diabetic neuropathy: a randomized, controlled study. Neurology 2001; 57: 505-9.

63. Ziegler D, Reljanovic M, Mehnert H, Gries FA. Alfa-Lipoic acid in the treatment of diabetic polyneuropathy in Germany: current evidence from clinical trials. Exp Clin Endocrinol Diabetes 1999; 107: 421-30.

64. Boulton AJM. Management of diabetic peripheral neuropathy. Clin Diab 2005; 23: 9-15. 